\title{
Análise do desempenho ocupacional de crianças e adolescentes com anemia falciforme*
}

\author{
Analysis of the occupational performance of \\ children and adolescents with sickle cell anemia
}

\author{
Nayara Bernardes Segava ${ }^{1}$, Alessandra Cavalcanti ${ }^{2}$
}

\begin{abstract}
SEGAVA, N. B., CAVALCANTI, A. Análise do desempenho ocupacional de crianças e adolescentes com anemia falciforme. Rev. Ter. Ocup. Univ. São Paulo, v. 22, n. 3, p. 279-288, set./dez. 2011.

RESUMO: A anemia falciforme (AF) configura-se como uma das doenças genéticas de maior frequência no mundo e no Brasil e vem sendo descrita apenas com relação às implicações na função e estrutura do corpo. Esta pesquisa teve como objetivo analisar o desempenho ocupacional de crianças/adolescentes com o diagnóstico de AF, investigando-se o impacto da patologia na condição de saúde destes. Os dados foram coletados através da Medida Canadense de Desempenho Ocupacional (COPM) junto a treze crianças/adolescentes e considerados a partir da técnica de análise de conteúdo. Verificou-se que as alterações obtidas no desempenho e na satisfação ocorrem não somente em decorrência da disfunção orgânica.
\end{abstract}

DESCRITORES: Anemia falciforme; Atividades cotidianas; Criança; Adolescente.

\footnotetext{
* Trabalho de Conclusão de Curso (TCC) do Curso de Terapia Ocupacional da Universidade Federal do Triângulo Mineiro (UFTM) aprovado pelo Comitê de Ética da UFTM de acordo com o protocolo n 1428.

1. Terapeuta Ocupacional pela UFTM; nasegava@gmail.com.

2. Prof $^{\mathrm{a}}$ Assistente I do Curso de Terapia Ocupacional da Universidade Federal do Triângulo Mineiro - UFTM. Pesquisadora do Laboratório Integrado de Tecnologia Assistiva (LITA/UFTM).

Endereço para correspondência: Universidade Federal do Triângulo Mineiro. Unidade Centro Educacional (CE). Curso de Terapia Ocupacional. Av. Getúlio Guaritá, s/n. $3^{\circ}$ Piso. Uberaba, MG. CEP: 38025-440. E-mail: lita@to.uftm.edu.br
} 


\section{INTRODUÇÃO}

doença falciforme (DF) é reconhecida pelo
Ministério da Saúde (MS) como uma das
doenças genéticas de maior frequência no Brasil e no mundo (BRASIL, 2009a). A anemia falciforme (AF) configura-se como um dos tipos de DF, e é causada por uma alteração genética e hereditária que determina uma anormalidade da hemoglobina presente nas hemácias, responsável pelo transporte de oxigênio a todas as partes do organismo. A anormalidade define-se em um novo formato das hemácias, que se tornam não circular (adquirindo o formato de meia lua ou foice), com incapacidade de se transpor pelos pequenos vasos sanguíneos, bloqueandoos e impedindo a circulação do sangue nas áreas ao redor (OLIVEIRA, 2001; ZAGO, 2001; BRASIL, 2006, 2007).

Assim a oxigenação do organismo se torna deficiente e consequentemente problemas como isquemia, dor, necrose tecidual e disfunções ocorrem, e, em estágios avançados danos permanentes em tecidos e órgãos essenciais ao funcionamento do corpo podem ser observados.

De acordo com dados obtidos pelo Programa Nacional de Triagem Neonatal (PNTN), nascem cerca de 3.500 crianças por ano com DF e 200.000 são portadoras do traço falciforme (possuem apenas um gene anormal - heterozigoto); sendo distribuída na população heterogeneamente, tendo uma maior frequência nos Estados que possuem um maior número de afrodescendentes e com o recorte social entre os mais pobres (BRASIL, 2009b).

O Estado de Minas Gerais apresenta um número significativo quanto à presença da doença na população. Segundo os dados do PNTN, a proporção de nascidos vivos diagnosticados com a DF é de 1:1.400 e com o traço falciforme é de 1:23 (BRASIL, 2008a, 2009b).

Uma vez diagnosticado a DF do tipo AF, as manifestações clínicas descritas são variadas, em alguns casos, assintomáticas e em outros de extrema gravidade, levando a complicações que podem chegar a afetar quase todos os órgãos e sistemas (BRASIL, 2007, 2009).

Estas manifestações são derivadas primariamente da oclusão vascular e, em menor grau da anemia. Os indivíduos com esse diagnóstico podem apresentar períodos sem manifestações clínicas denominadas "fase estável" da doença, sendo que esta fase pode ser interrompida por manifestações agudas, como as crises vaso-oclusivas ou dolorosas (secundária à falcização das hemácias) (COSTA, 2004). A dor ocasionada em decorrência destas crises se torna um fator limitante para o desempenho de atividades.

A variabilidade clínica é advinda da influência de fatores hereditários, características próprias do indivíduo (fatores do cliente), contextuais e ambientais, tais como as condições socioeconômicas, que determinam as categorias de moradia, trabalho, alimentação, prevenção e assistência médica (ZAGO, 2001).

A dificuldade que o indivíduo com $\mathrm{AF}$ pode encontrar na execução de tarefas e os problemas que pode enfrentar ao se envolver em situações comuns do dia-a-dia ampliam a fragilidade da sua condição de saúde.

A condição de saúde passou a ser compreendida em nova perspectiva pela Organização Mundial de Saúde (OMS, 2003). A preocupação sobre o que "uma pessoa com uma doença ou perturbação faz ou pode fazer" (OPAS/ OMS, 2003, p.07), e não somente quais as consequências da doença, passou a ser considerada. A nova linguagem se encontra na Classificação Internacional de Funcionalidade, Incapacidade e Saúde (CIF) que complementa a estrutura etiológica das doenças, descritas pela Classificação Internacional de Doenças, Décima Revisão (CID-10) (OPAS/ OMS, 2003).

Nessa perspectiva as pessoas com AF podem apresentar distintos níveis de funcionalidade ou de incapacidade, determinados não somente pelas manifestações clínicas (funções e estruturas do corpo), mas também pelo nível de participação e envolvimento em atividades nos diferentes contextos.

Neste estudo se avalia impacto da AF na condição geral de saúde de crianças e adolescentes, e a forma como desempenham suas ocupações. Buscou-se compreender as possíveis limitações impostas pela $\mathrm{AF}$, que impedem o envolvimento em ocupações significativas e em atividades desejadas e/ou necessárias.

Compreende-se o desempenho ocupacional como a capacidade de realizar as tarefas que possibilitam a execução de papéis ocupacionais e sociais de maneira satisfatória e apropriada para o estágio de desenvolvimento, cultura e ambiente do indivíduo (PEDRETTY; EARLY, 2005). Pode ser avaliado por terapeutas ocupacionais por meio da Medida Canadense de Desempenho Ocupacional (COPM).

\section{PERCURSOS METODOLÓGICOS}

Realizou-se uma pesquisa exploratória do tipo quanti-qualitativa, delineada como estudo de caso, através de emprego de entrevista semi-estruturada denominada Medida Canadense de Desempenho Ocupacional (COPM), com tomada de nota e gravação.

A COPM mede a percepção do cliente sobre seu desempenho ocupacional, resultado da interação entre a pessoa, o ambiente e a ocupação. As ocupações são categorizadas em: autocuidado (cuidado pessoal, mobilidade funcional e o funcionamento na comunidade); produtividade 
(trabalho remunerado ou não, manejo das tarefas domésticas, escola e brincar); lazer (recreação tranquila, recreação ativa e socialização). Estas categorias da COPM são abertas e permitem que o terapeuta ocupacional explore as diversas áreas de ocupação (LAW et al., 2009).

A amostra foi constituída a partir de um levantamento, junto a uma instituição que atende indivíduos com AF, que identificou 13 crianças/adolescentes com o diagnóstico. O protocolo de entrevista da COPM foi aplicado junto a essas crianças/adolescentes após aprovação da pesquisa pelo Comitê de Ética e Pesquisa da UFTM (parecer ${ }^{\circ}$ 1428/10).

A coleta de dados ocorreu entre os meses de fevereiro e março de 2010 e cada criança/adolescente e respectivo responsável foram informados acerca dos objetivos e procedimentos do estudo e sobre o Termo de Consentimento Livre e Esclarecido. Um teste piloto foi conduzido a fim de detectar possíveis necessidades de modificação na abordagem da entrevista e/ou na linguagem da avaliação.

Após a coleta dos dados, usando o protocolo de entrevista da COPM, procedeu-se a análise e interpretação que empregou a técnica de 'análise de conteúdo' (BARDIN, 2010). Utilizaram-se unidades de registro pré-estabelecidas (categorias tituladas na COPM), registrando-se a ocorrência e frequência dos elementos nos depoimentos de cada sujeito do estudo, os quais foram apresentados com a seguinte legenda: $\mathrm{E}_{1}$ : entrevista 1; $\mathrm{E}_{2}$ : entrevista 2, e assim consecutivamente (MINAYO, 2006).

\section{RESULTADOS E DISCUSSÃO}

Entendendo a saúde como relacionada ao conjunto de fatores que define a funcionalidade do indivíduo, no caso deste estudo crianças/adolescentes com AF; os sujeitos pesquisados apresentam uma patologia que afeta funções e estruturas do corpo.

A Política Nacional de Saúde da Pessoa Portadora de Deficiência esclarece que algumas patologias não se enquadram como deficiências na classificação da OMS, no entanto, repercutem direta ou indiretamente na condição de saúde e estados relacionados a ela, sejam em graus variáveis de limitação de atividades ou de restrição de participação, como é o caso daqueles com diagnóstico de AF (BRASIL, 2008b).

Sobre essa perspectiva, sendo a AF uma patologia crônica, espera-se que os indivíduos tenham saúde e bemestar, pois "a saúde se promove proporcionando condições de vida decentes, boas condições de trabalho, educação, cultura física e formas de lazer e descanso" (SIGERIST, 1946 apud ROSEN, 1979 apud BUSS, 2000, p. 166). Neste estudo as crianças e adolescentes entrevistados não relataram uma condição de saúde e bem-estar satisfatória.

Os resultados revelam os problemas, preocupações e questões relativas ao desempenho ocupacional das crianças e adolescentes com diagnóstico de $\mathrm{AF}$, realizado através da aplicação da COPM. A COPM adota como parâmetro para o escore de desempenho (1 a 10), sendo o escore 1 entendido como 'incapaz de fazer' e o escore 10 como 'capaz de fazer extremamente bem'. O mesmo se aplica ao escore de satisfação, sendo compreendido respectivamente como, escore 1 'nada satisfeito' e 10 'extremamente satisfeito'.

O escore de desempenho e o escore de satisfação apresentaram-se baixos, conforme visualização nos Gráficos 1 e 2.

Gráfico 1- Desempenho ocupacional relativo ao número de sujeitos

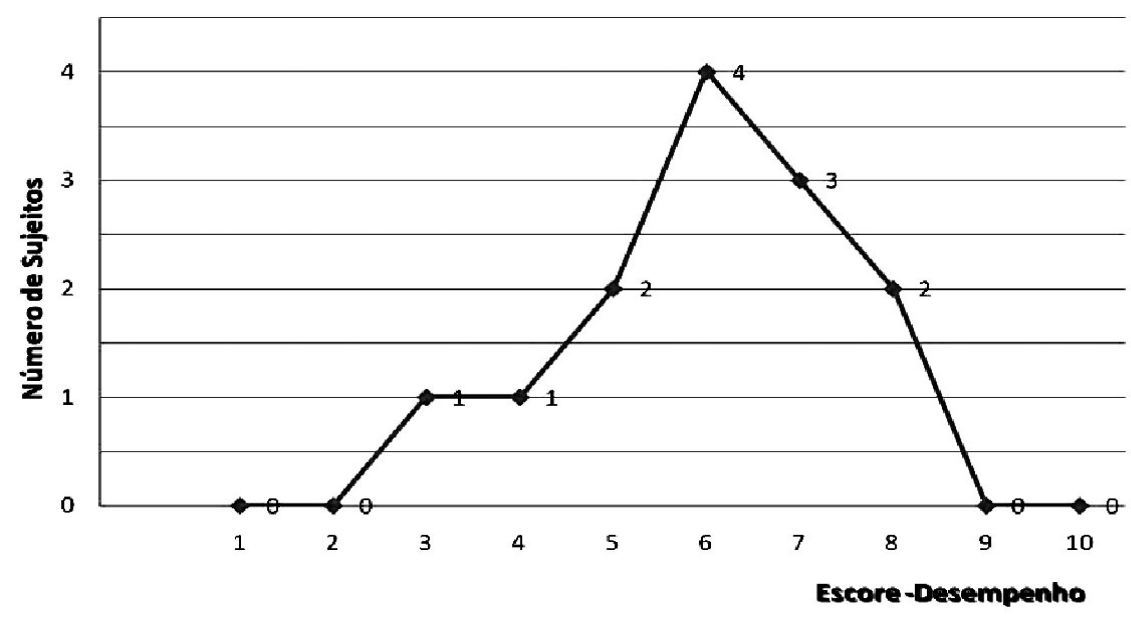


Gráfico 2 - Pontuação da satisfação por número de sujeitos

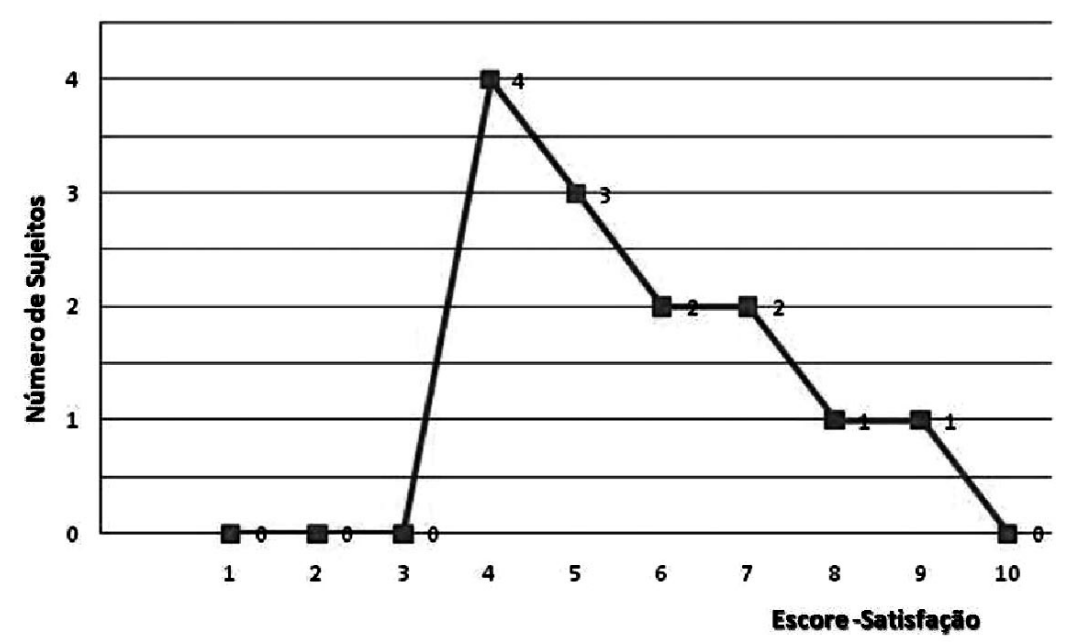

A partir da análise dos gráficos, verifica-se uma variação da pontuação em relação ao número de sujeitos entrevistados para desempenho (escore: 3 a 8 ) e para satisfação (escore: 4 a 9); e tem-se a média de desempenho em escore 6 e de satisfação em escore 4.

Esta variação pode ser entendida pela composição da amostra, que contemplou crianças e adolescentes em ampla faixa etária (Gráfico 3), como também pode ser justificada pelos fatores contextuais e pessoais de cada sujeito, como a condição sócio-econômica, o ambiente físico e social, e as percepções culturais, além das condições clínicas que caracterizam a AF.

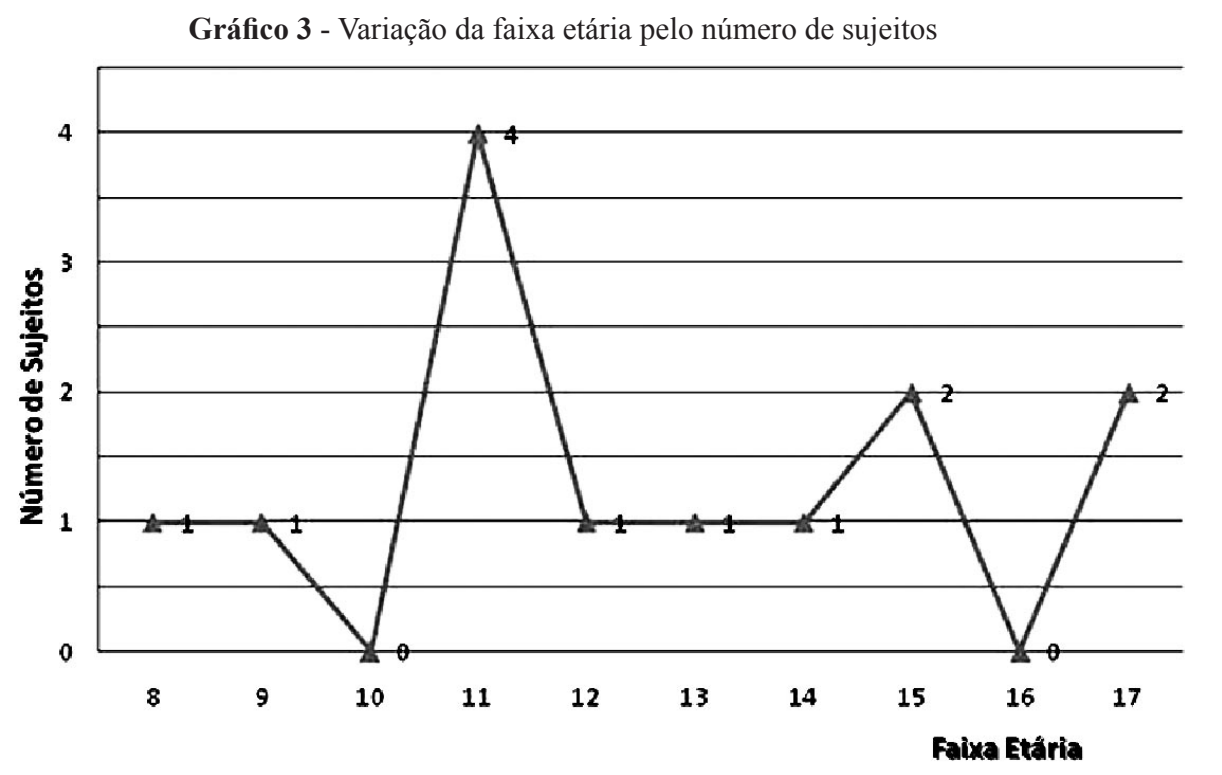

$\mathrm{Na}$ identificação das atividades do dia-a-dia que as crianças/adolescentes desejam, necessitam ou esperam realizar, as áreas do desempenho analisadas foram às categorias da COPM.

Das atividades de autocuidado, foram ressaltados os domínios cuidados pessoais e mobilidade funcional. Nos cuidados pessoais foram relatadas como particularidades pelos participantes do estudo: (1) a alimentação; (2) o vestuário/ banho/ higiene pessoal; e (3) o sono.

A alimentação, definida como o processo de colocar, trazer a comida até a boca (AOTA, 2008), foi referida em 6 das entrevistas realizadas. Para esses participantes existe 
restrição alimentar vinculada a alguns alimentos que não podem ser ingeridos, tais como: alimentos ácidos, gelados e gordurosos:

“(...) não posso tomar coisa gelada, no caso, de eu tomar muito, ai eu como na hora não dá nada, ai passa e depois de uma semana começa... Mãe está doendo minha garganta, está doendo minha barriga, ai começa a me dar crise. E se eu comer pode me dar dor de cabeça, dor no braço". $E_{8}$

"Algumas coisas a gente não pode comer. Suco de limão, abacaxi... mas a gente come só de vez em quando (...) também não posso comer carne de porco porque depois eu passo mal, minha barriga começa a inchar". $E_{3}$

Observa-se que os sujeitos entrevistados incorporam que alguns alimentos fazem mal ou são desencadeadores de dor/crise, como os alimentos ácidos, alimentos gordurosos e alimentos gelados. Esta situação interfere nos hábitos alimentares das crianças/adolescentes e em sua satisfação e hábitos alimentares.

Entretanto, a literatura aponta para restrições alimentares apenas em situações em que os indivíduos com AF necessitam de transfusões recorrentes, o que gera acúmulo de ferro (CANÇADO, 2007). Assim, exceto em tais situações, que requerem acompanhamento nutricional, não há restrições alimentares recomendadas aos indivíduos com AF.

A segunda questão relatada no domínio cuidados pessoal foi o vestuário/banho/higiene pessoal referido por três dos entrevistados. O vestuário compreende a capacidade de despir-se e vestir-se adequadamente; enquanto o banho refere-se à capacidade de obtenção e utilização de equipamentos para ensaboar, enxaguar e secar o corpo; e a higiene pessoal é a capacidade para obter e usar suprimentos, e cuidar de partes do corpo como pele, orelhas, olhos, nariz, boca e cabelo (AOTA, 2008).

Em todas as entrevistas foi ressaltada a limitação na realização destas atividades devido aos processos álgicos. Para serem efetivadas necessitam de auxílio de cuidadores, porém, estas limitações ocorrem somente na presença desses processos:

\footnotetext{
"Teve uma vez que eu estava com muita dor, acho que era na barriga, (...) dai eu nem dei conta de tomar banho, sozinha, aí a minha mãe ou o meu pai me pega no colo e me leva no banheiro, até tem uma cadeira lá pra eu sentar". $E_{8}$

"Às vezes se for para eu colocar uma blusa assim de
}

\section{frio, ai eu preciso de ajuda, dependendo de onde é a dor} também né". $E_{9}$

Em geral os episódios de dor são autolimitados, com variações de intensidade e duração e acometem principalmente a região lombar, ossos longos e articulações (NAOUM; NAOUM, 2004). Costa (2004) acresce que a frequência e a gravidade da dor são variáveis para cada paciente e inclusive, pode ser distinta no mesmo paciente, em diferentes períodos de sua vida. Os fatores desencadeantes são inúmeros: infecção, desidratação, tensão emocional, hipóxia, acidose, bem como pela mudança brusca na temperatura (COSTA, 2004; NAOUM; NAOUM, 2004).

O terceiro tema referido por 7 participantes, está no domínio cuidados pessoal foi o sono. De acordo com os discursos dos participantes, identificaram-se 2 aspectos: 1) a dor é a responsável pela interrupção do sono, despertando o sujeito e interrompendo o período de sono restaurativo; e 2) a dor não permite que a criança/adolescente inicie o período de descanso, mantendo-o em estado de alerta e consequentemente, levando-o ao cansaço no dia que se segue:

“(...) teve uma vez que eu estava em crise, eu acordei estava sentindo muita dor que eu não agüentei, ai eu falei assim "nossa mãe, pelo amor de Deus me leva pro hospital que eu estou sentindo muita dor". Ai ela falou assim "não eu não vou te levar agora não", fez uma massagem na minha barriga e me deu um remédio que a médica me passou pra dor, ai eu comecei a melhorar e consegui dormir direitinho". $E_{5}$

"Eu durmo bem. Mas depende de onde vem a crise, a crise mais forte é na barriga, ai eu não consigo dormir”. $E_{9}$

De acordo com a AOTA (2008) dormir e descansar são áreas de ocupação, sendo o sono compreendido como atividade resultante do ir dormir, ficar adormecido e garantir saúde e segurança através da participação. Nos sujeitos entrevistados identificou-se limitação neste aspecto , pois estes enfrentam impedimentos nos momentos de crises álgicas de realizar o sono restaurativo necessário para a saúde e o envolvimento em demais ocupações, ou seja, seu envolvimento em outros contextos (OPAS/OMS, 2003).

A mobilidade funcional referente ao domínio autocuidado enfoca dois campos, o primeiro denominado de 'mobilidade funcional', se refere as atividades de vida diária e o segundo, denominado de 'mobilidade na comunidade', se refere as atividades instrumentais da vida diária. 
A 'mobilidade funcional' diz respeito à capacidade de mover-se de uma posição para outra: na cama, na cadeira de rodas, em transferências e a deambulação funcional, sendo que se aplica aos indivíduos estudados somente o item deambulação funcional. Já a mobilidade na comunidade, distingue-se da anterior por descrever deslocamentos na comunidade, como o uso dos meios de transportes, o que também foi evidenciado pelos participantes da pesquisa (AOTA, 2008).

Neste domínio oito participantes referiram limitação por dor. Assim como para os cuidados pessoais, a dor no domínio mobilidade funcional se estabeleceu como um fator incapacitante para participação em atividades rotineiras, sendo o "andar" comentado pelos sujeitos como limitado em episódios de crises álgicas:

\footnotetext{
"De vez em quando, quando eu sinto dor na coluna eu fico gemendo aí eu não dou conta de andar direito". $E_{12}$
}

“(...) dependendo de onde é a dor se for, por exemplo, na perna eu sinto dificuldade pra andar, é muito dependente de onde é a dor". $E_{9}$

Alguns ainda expuseram que a própria 'mobilidade funcional' em demasia em um período do dia é fator que incita os processos de crise e, restringe o envolvimento em atividades habituais como caminhadas à longa distância:

“(...) quando eu subo um morro, eu fico com falta de ar, à noite essa perna minha dói”. $E_{1}$

No domínio autocuidado - independência fora de casa, os sujeitos não apresentaram relatos.

$\mathrm{Na}$ segunda categoria, apresentada pela COPM, foram ponderados todos os domínios trabalho, tarefas domésticas e escola/brincar.

O domínio produtividade - trabalho remunerado/ não remunerado foi abordado por 3 dos entrevistados, em decorrência da faixa etária do grupo pesquisado em questão, em que há um predomínio de crianças com idade inferior aos quatorze anos de idade (Gráfico 3) que, portanto ainda não possuem envolvimento nesta ocupação.

A área de ocupação - trabalho inclui atividades necessárias para o envolvimento remunerado em empregos ou atividades voluntárias (AOTA, 2008), sendo identificado pelos participantes como uma atividade em que os mesmos estão limitados, sobretudo por não poderem "pegar peso:

“(...) então porque a gente não pode pegar muito peso, senão dá dor, então qualquer serviço tem algum problema". $E_{11}$

Sabe-se que quando uma pessoa se exercita, seu corpo requer maior quantidade de oxigênio. $\mathrm{Na} A \mathrm{AF}$ os indivíduos possuem uma limitação no consumo de oxigênio durante atividades que exigem vigor. Isto ocorre em decorrência de mecanismos centrais (pulmonar e cardiovascular) na afinidade da hemoglobina por oxigênio que na AF encontra-se alterada; da pressão sanguínea arterial que pode sofrer interrupções após vaso-oclusão; e de mecanismos periféricos (circulação local) como o fluxo sanguíneo muscular, que também pode estar diminuído (MAUGHAN et al., 2000).

Sobre a mesma perspectiva alguns adolescentes apontaram as variações na temperatura, principalmente para o calor, como um fator limitante para inserção no trabalho:

\footnotetext{
“Trabalhar não pode né. É, porque não pode ficar no sol. Uma vez minha mãe ia me colocar no Probem, dai ela fez um atestado falando que eu não podia ficar no sol, fazer aquilo, dai eles falaram então não tem jeito né, ela não pode ficar em lugar nenhum". $E_{9}$
}

A inabilidade de concentrar urina, que leva a perda de líquidos e a desidratação rápida, pode ser entendida pelo possível comprometimento das funções geniturinárias pois o rim apresenta um microambiente propício para o processo de falcização devido às reduzidas tensões de oxigênio (COSTA, 2004).

Por isso, em situações de temperatura elevada, a hidratação deve ser considerada para que não favoreça o processo de falcização, e, consequentemente, induza as crises de dor.

O que se percebe nas entrevistas é que a maioria dos sujeitos não possui clareza sobre a necessidade do balanço hídrico regular, principalmente em episódios de calor excessivo. Desta forma, tanto o exercício físico, 'pegar peso', como o 'calor' se tornam fatores limitantes para o envolvimento em atividades de trabalho.

As tarefas domésticas (atividades que apóiam a vida diária dentro da casa e da comunidade (AOTA, 2008), também foram descritas por 4 dos entrevistados como limitadas por favorecerem o aparecimento de dor em situações que demandam a realização de tarefas que necessitam 'pegar peso':

\footnotetext{
"Eu gosto muito de lavar a casa só que eu não posso porque assim eu tenho que jogar água com o balde e dai eu já estou pegando peso". $E_{8}$
} 
Além da limitação para a realização de atividades que deverão pegar e/ou carregar peso, as crianças/ adolescentes relataram o aparecimento do quadro álgico, nas tarefas domésticas que demandam o uso da água fria, como lavar louça, roupa e o quintal:

“(...) dai quando tem alguma coisa para lavar, eu lavo louça, mas também eu não lavo exageradamente porque depois me dá dor... Não é muito bom ficar muito tempo pondo a mão na água gelada... eu também lavo roupa... assim pecinhas minhas (...)". $E_{6}$

Em relação à escola, três crianças e adolescentes relataram faltas frequentes causadas pelos períodos de crises:

"As faltas me atrapalha um pouco, mas daí com bastante reforço dá pra passar, mas às vezes prejudica um pouco, porque dai você perde matéria... o mês passado eu faltei uma semana seguida". $E_{9}$

Nota-se que em virtude do quadro recorrente e dos comprometimentos associados à patologia, por vezes as crianças/adolescentes tem suas atividades habituais alteradas . O absenteísmo escolar, devido às internações, influencia negativamente tanto o aprendizado escolar quanto a restrição de participação do meio social, inibindo o usufruto de direitos. (BRASIL, 2008c).

Ainda nas atividades escolares nove crianças/ adolescentes disseram ter restrições pontuando com baixo escore o desempenho e a satisfação para a participação na educação física:

"Eu participo, só que quando eu jogo futebol ou corro muito aí eu vou ficando cansada, dai eu paro um pouco, vou tomo água e depois eu volto". $E_{6}$

As mesmas queixas para desempenho e satisfação referidas para as atividades da educação física se configuraram em relação ao brincar, sendo ponderadas por 10 dos sujeitos:

“(...) quando eu estou andando de bicicleta eu fico cansado". $E_{12}$

Em todas as narrativas, verifica-se que o cansaço originado em tarefas que demandam esforço físico restringe as crianças/adolescentes no envolvimento satisfatório da ocupação/atividade. Moreira et al. (2002) relatam que isso pode ser atribuído em decorrência da $\mathrm{AF}$, pois ocorrendo à dispnéia o cansaço é frequente.

Ressalta-se também no domínio escola/brincar restrição em decorrência das variações climáticas, principalmente o sol. Na mesma perspectiva de restrição narrada no domínio trabalho, o desequilíbrio no balanço hídrico é um fator predisponente à crise vaso-oclusiva e consequentemente a dor limitará o envolvimento em brincadeiras que sejam expostos ao sol:

“Pipa, no sol quente eu não posso”. $E_{4}$

No domínio lazer - recreação tranquila, os participantes não apresentaram queixas e o domínio lazer - recreação ativa 10 dos entrevistados relataram restrições para realizar a atividade de natação.

“(...) eu não posso ficar muito tempo nadando, por exemplo, se eu estou no sol agora daí eu não posso entrar na água porque eu sei que eu vou sentir dor. Mas dai depois, por exemplo, se eu parar um pouquinho na sombra até a minha cabeça esfriar ai eu posso (...)". $E_{5}$

Entende-se que devido à alteração brusca na temperatura corporal em decorrência da temperatura da água, estes indivíduos são acometidos por dor, assim como descrito antes nas tarefas domésticas, onde a variação brusca na temperatura ambiental é fator predisponente para a crise da falcização.

No que concerne o domínio lazer-recreação ativa, além da atividade de natação é evidenciada as limitações nas atividades que se caracterizam pelo esforço físico, com envolvimento global do corpo, como a dança e a capoeira:

"Eu amo dançar, mas dançar muito eu não posso, porque depois de um tempo eu começo a ficar cansada e me dá dor nas pernas". $E_{6}$

"Eu não posso fazer capoeira, eu fazia, mas parei porque estava inchando as minhas pernas”. $E_{3}$

Para explicar essa limitação há a hipótese de que o exercício físico praticado em demasiado pelo sujeito com AF produz mudanças fisiológicas que induzem o processo de falcização das hemoglobinas devido aos fatores predisponentes, como a desidratação, o aumento na temperatura corporal, a hipóxia e a acidose, que ocorrem durante a prática do exercício (KLUG, 1974 apud MOREIRA et al., 2002). 
Por outro lado, Moreira et al. (2002) destacam que a restrição para o desenvolvimento da atividade física é particular e dependerá do limite físico de cada indivíduo, bem como do desejo de se envolver no exercício oferecido. Um baixo limite físico pode estar associado à anemia crônica e/ou a uma disfunção cardíaca que esses indivíduos diagnosticados com AF podem apresentar.

Os apontamentos referentes às variações climáticas também são enfatizados no domínio lazer - socialização. A socialização é definida como o envolvimento em atividades que resultam em interações sucedidas no nível comunitário, familiar e outros (AOTA, 2008). Os sujeitos relataram restrição para o desempenho de atividades rotineiras, como uma tarefa junto à família devido à possibilidade de aparecimento de quadro álgico (dor), muitas das vezes em decorrência das interferências climáticas (variações de temperatura), sendo relatado por cinco sujeitos entrevistados.

"Eu não posso é ficar quando está chovendo. Meu pai me chama para ajudar ele, só que eu não posso”. $E_{12}$

Os participantes descrevem as variações sazonais como fator que os restringem, no envolvimento em atividades de lazer, o que perpetua para a restrição da participação social, seja na comunidade, na família ou no relacionamento com outros. As mudanças bruscas na temperatura podem gerar o aparecimento de crises de falcização, e, consequentemente de dor, da mesma forma que ocorre quando se envolvem em atividades de natação onde terão contato com a água fria.

Assim, os problemas de desempenho descritos; isto é, as atividades e ocupações difíceis de serem realizadas de forma satisfatória, não possuem completa analogia com a clínica da anemia falciforme. Observa-se que as alterações obtidas no desempenho e na satisfação ocorrem em grande parte à falta de esclarecimentos e informações acerca da própria patologia.

\section{CONSIDERAÇÕES FINAIS}

Sobre a nova perspectiva de saúde e estados relacionados à saúde enfatizados pela $\mathrm{CIF}(\mathrm{OPAS} / \mathrm{OMS}$, 2003), pessoas com diagnóstico de $\mathrm{AF}$ apresentarão déficits em sua condição de saúde e nos estados relacionados a ela (incapacidade) que interferem na capacidade de desempenho/execução de tarefas, gerando assim limitação da atividade e restrição na participação.

$\mathrm{Na}$ bibliografia consultada não foram identificadas discussões acerca da capacidade de execução de tarefas e/ ou limitações de atividades e restrições na participação das pessoas com AF. Não existindo delimitação do(s) aspecto(s) da funcionalidade e o/u incapacidade da doença, uma vez que as descrições existentes são exclusivamente das alterações nos sistemas corporais (fatores do cliente).

Neste trabalho verificou-se que a incapacidade (limitação das atividades e restrição na participação) pode ser resultante de falha nas informações e esclarecimentos acerca da $\mathrm{AF}$ e não somente em decorrência da interação entre a disfunção orgânica ou das estruturas e funções do corpo.

Salienta-se que isto não pode ser generalizado para todos os indivíduos com esse diagnóstico, pois na amostra estudada há peculiaridades, como a condição socioeconômica, o meio em que estão inseridos, e suas percepções culturais, bem como, o contexto familiar que pode influenciar na restrição de envolvimento em atividades do dia-a-dia, por condutas protetoras.

Apesar disso, verificou-se dificuldade na execução de tarefas e identificaram-se problemas que enfrentam ao se envolver em situações comuns do dia-a-dia, o que amplia a fragilidade da condição de saúde dessas crianças e adolescentes, inibindo-os de se envolverem em ocupações significativas de seu contexto.

A terapia ocupacional pode auxiliar as pessoas a se envolverem nas ocupações e/ou atividades da vida diária, importantes e significativas para elas com o intuito de manter seu estado de saúde e bem-estar. O envolvimento na ocupação é visto como algo que naturalmente apóia e leva à participação do indivíduo em seu contexto (AOTA, 2008).

Frente a isto, constata-se a necessidade de desenvolvimento de ações e estratégias para esclarecer sobre as reais imposições da anemia falciforme na condição de saúde de seus portadores. A educação deve abranger esclarecimentos tanto para as crianças/adolescentes quanto para familiares e cuidadores, e agregar valor sobre a patologia e os fatores predisponentes de crises de falcização, bem como, tem-se a necessidade de desmistificar concepções e condutas que não possuem relação com a doença, como no caso da restrição alimentar.

Os dados contribuem para a realização de parcerias com instituições que atendam a esta demanda, na criação de novos projetos, como os extensionistas vinculados à instituições de ensino. As ações voltadas para essa clientela deveriam enfocar na educação e esclarecimento das possibilidades de execução das atividades diárias, bem como, nas possibilidades de participação e envolvimento em tarefas do dia-a-dia no que se refere às atividades produtivas, de autocuidado e de lazer, promovendo assim a qualidade de vida e o desempenho ocupacional satisfatório. 
SEGAVA, N. B.; CAVALCANTI, A. Analysis of the occupational performance of children and adolescents with sickle cell anemia. Rev. Ter. Ocup. Univ. São Paulo, v. 22, n. 3, p. 279-288, set./dez. 2011

\begin{abstract}
Sickle cell anemia (SCA) configures itself as one of the genetic illness of a major frequency in the world and in the Brazil and the disease has been described only in relation to its implications in the function and structure of the body. This research aimed to analyze the occupational performance of children/adolescents with a diagnostic of SCA, investigating the impact of the pathology in the condition of their health. The data were collected through the Canadian Occupational Performance Measure (COPM) with thirteen children/adolescent, and were considered from analysis of the content. It was verified that the alterations obtained in the performance and in the satisfaction not only occur as a result of organic dysfunction.
\end{abstract}

KEY WORDS: Anemia, sickle cell; Activities of daily living; Child; Adolescent.

\title{
REFERÊNCIAS
}

AOTA-American Occupational Therapy Association. Occupational Therapy Practice Framework: Domain And Process. Am. J. Occup. Ther., v. 62, n. 6, p. 625-683, 2008.

BARDIN, L. Análise do conteúdo. Lisboa: Edições70, 2010.

BRASIL. Ministério da Saúde. Estatuto da Criança e do Adolescente. 3a. Ed. Brasília, 2008c.

BRASIL. Ministério da Saúde. Secretaria de Atenção à Saúde. Manual da anemia falciforme para a população. Brasília, 2007.

BRASIL. Ministério da Saúde. Secretaria de Atenção à Saúde. Manual de condutas básicas na doença. Brasília, 2006.

BRASIL. Ministério da Saúde. Secretaria de Atenção à Saúde. Manual de Educação em Saúde - Volume 1: autocuidado na doença falciforme. Brasília, 2008a.

BRASIL. Ministério da Saúde. Secretaria de Atenção à Saúde. Manual de Educação em Saúde - Volume 2: linha de cuidado em doença falciforme. Brasília, 2009b.

BRASIL. Ministério da Saúde. Secretaria de Atenção à Saúde. Manual de eventos agudos em doença falciforme. Brasília, 2009a.

BRASIL. Ministério da Saúde. Secretaria de Atenção à Saúde. Política Nacional de Saúde da Pessoa Portadora de Deficiência. Brasília: Ministério da Saúde, 2008b. [Acesso em 5 maio 2010]. Disponível em: $<$ http://bvsms.saude.gov.br/bvs/publicacoes/ politica_nacional_saude_pessoa_deficiencia.pdf $>$.
BUSS, P. M. Promoção da saúde e qualidade de vida. Ciênc. Saúde Coletiva, v. 5, n. 1, p. 163-177, 2000.

CANÇADO, R. D. Sobrecarga e quelação de ferro na anemia falciforme. Rev. Bras. Hematol. Hemoter, v. 29, n. 3, p. 316-326, 2007.

COSTA, F. F. Anemia falciforme. In: ZAGO, M. A.; FALCÃO, R. P.; PASQUINI, R. Hematologia: fundamentos e prática. São Paulo: Atheneu, 2004. p. 289-308.

LAW, M.; et al. Medida Canadense de Desempenho Ocupacional (COPM). Trad. Ana Amélia Cardoso, Lílian Magalhães, Lívia de Castro Magalhães. Belo Horizonte: Editora UFMG, 2009.

MAUGHAN, R.; GLEESON, M.; GREENHAFF, P. L. Fisiologia e bioquímica do músculo esquelético e do exercício. In: MAUGHAN, R.; GLEESON, M.; GREENHAFF, P. L. Bioquímica do exercício e treinamento. São Paulo: Manole, 2000. p. 01-46.

MINAYO, M. C. S. Técnicas de análise do material qualitativo. In: MINAYO, M. C. S. O desafio do conhecimento: pesquisa qualitativa em saúde. 9a.ed. São Paulo: Hucitec, 2006. p. 303360 .

MOREIRA, G. F.; et al. Aspectos fisiológicos da atividade física em portadores de anemia falciforme. 2002. $31 \mathrm{f}$. Trabalho de Conclusão de Curso (Especialização) - Universidade Federal de São Paulo, São Paulo, 2002.

NAOUM, P. C.; NAOUM, F. A. Manifestações clínicas da doença 
SEGAVA, N. B., CAVAlCANTI, A. Análise do desempenho. Rev. Ter. Ocup. Univ. São Paulo, v. 22, n. 3, p. $279-288$, set./dez. 2011.

falciforme e tratamento específico. In: NAOUM, P. C.; NAOUM, F. A. Doenças das células falciformes. São Paulo: Sarvier, 2004. p. $133-169$.

OLIVEIRA, F. Singularidades: Anemia Falciforme. In: BRASIL. ORGANIZAÇÃO PAN-AMERICANA DA SAÚDE. Saúde da população negra. Brasília: OPAS, 2001. p. 125-135.

OPAS/OMS. CIF: Classificação internacional de funcionalidade, incapacidade e saúde. São Paulo: Editora USP, 2003.
PEDRETTY, L. W.; EARLY, M.B. Desempenho ocupacional e modelos de prática para disfunção física. In: PEDRETTY, L. W.; EARLY, M. B. Terapia ocupacional. 5a.ed. São Paulo: Roca, 2004. p. 3-13.

ZAGO, M. A. Anemia falciforme e doenças falciformes. In: ZAGO, M. A. Manual de doenças mais importantes, por razões étnicas, na população brasileira afro-descendente. Brasília: Ministério da Saúde, 2001. p. 13-36. 